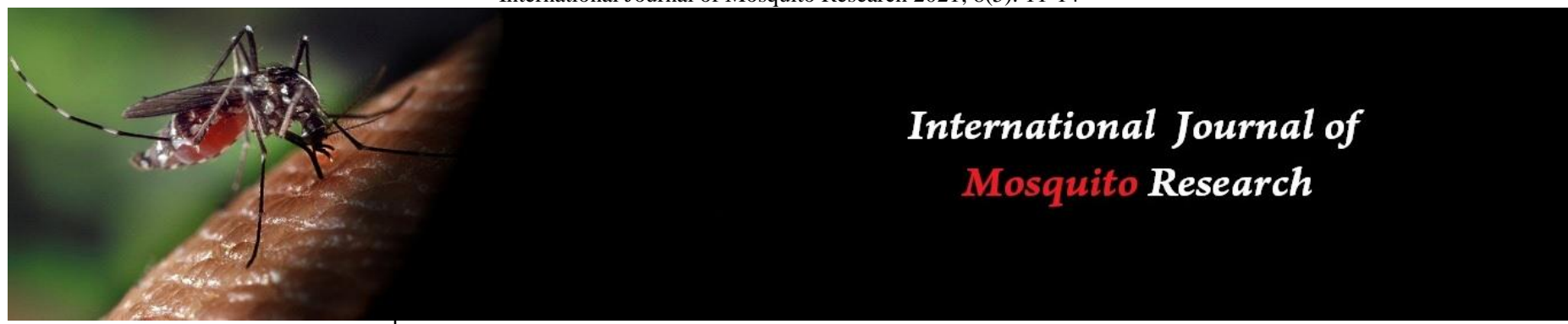

ISSN: 2348-5906

CODEN: IJMRK2

IJMR 2021; 8(5): 11-14

(C) 2021 IJMR

www.dipterajournal.com

Received: 07-07-2021

Accepted: 09-08-2021

Deepak Choudhary ICMR-National Institute of Implementation Research for Non-Communicable Diseases, Jodhpur, Rajasthan, India

Karam Vir Singh

ICMR-National Institute of Implementation Research for Non-Communicable Diseases, Jodhpur, Rajasthan, Rajasthan, India

\section{Insecticide resistance status of important malaria vectors in a tribal district of Rajasthan}

\section{Deepak Choudhary and Karam Vir Singh}

DOI: https://doi.org/10.22271/23487941.2021.v8.i5a.556

\title{
Abstract
}

Investigations have been carried-out in a malaria prone district of Rajasthan to determine insecticide resistance status of important malaria vector species viz. Anopheles culicifacies, An. annularis and An. stephensi, against insecticides being used under National Malaria Control Programme in two Block Public Health Centres of Banswara district of Rajasthan. An. culicifaies, except one canal irrigated village, where it was found susceptible to DDT, was found either resistant or intermediate resistant. Against Malathion An. culicifacies was found susceptible in one rain-fed irrigation village, whereas in all other villages, it was found either resistant or intermediate resistant. Against synthetic pyrethroids $A n$. culicifacies was found susceptible to both Alpha Cypermethrin and Cyfluthrin, except one rain-fed irrigation village, where against Cyfluthrin, the species exhibited intermediate resistance. This is a first report of synthetic pyrethroid resistance from Rajasthan. An. annularis, was found resistant to DDT in both canal irrigated and rain-fed irrigation villages, however, against Malathion it exhibited resistance in canal irrigated village and intermediate resistance in rain-fed irrigation village, however, against Alpha Cypermethrin and Cyfluthrin the species was found totally susceptible in both the areas. An, stephensi was tested only against Alpha Cypermethrin in a canal irrigated village and found totally susceptible. In the study area An. culicifacies have exhibited triple resistance, showing resistance to DDT, Malathion and intermediate resistance to cyfluthrin, however, An. annularis exhibited double resistance to DDT and Malathion.

Keywords: insecticide resistance, malaria vectors, DDT, Malathion, synthetic pyrethroids, Rajasthan

\section{Introduction}

Vector control using insecticides of public health importance has been the only effective mean for the prevention of malaria. However, precipitation of insecticide resistance among malaria vector species has posed challenge to the managers of vector control programmes the world over. For the want of malaria vaccine and development of drug resistance in malaria parasites have not left other option for the prevention and control of malaria, but the use of insecticides [1]. Since insecticides too, due to development of resistance among anopheline vectors and cross-tolerance due to insecticides of agricultural use, have alarmed the programme managers to use insecticides against vector species very judiciously ${ }^{[2]}$. The determination of the current status of insecticide resistance of vector populations against individual insecticides being parts of national control programmes either as indoor residual spray (IRS), in insecticide impregnated bed nets (IIBN) or as larvicide, becomes utmost import for monitoring and management purposes in view of making mid-term corrections. World Health Organization (WHO) too, considering the importance of insecticide resistance propounded Global Plan for Insecticide Resistance Management (GPIRM) for technical upgradation ${ }^{[3]}$. Considering above a study was carried-out in a malaria prone district of Rajasthan to determine insecticide resistance status of important malaria vector species against insecticides being used under National Malaria Control Programme, and the findings have been presented in the present communication.

\section{Material \& Methods}

The studies were carried-out in two Block Public Health Centres (BPHCs) of Banswara district i.e Kushalgarh, representing rain-fed area and Partapur, a canal irrigated area, which were 
selected on the basis of malaria prevalence of last year. In Partapur BPHC, canal irrigated area, two villages viz. Bhagora and Kheda, where adequate numbers of freshly fed females of anopheline species were collected for conducting the insecticide resistance tests, whereas, in Kushalgarh BPHC, three villages viz. Potalia, Kotda and Khajura, were included in the study. All the study villages had insecticide spray history of DDT.

The mosquito collection was conducted in the study villages during dawn hours using aspirator tube and torch light to collect the maximum numbers of freshly fed individuals. The collected anophelines were transported to the field laboratory in Burraud cages. The experimental anophelines were put on glucose diet before conducting tests for 8-10 hours and the damaged individuals were removed.

The tests were conducted as per the WHO Standard Method [4]. The tests were conducted against diagnostic doses of DDT (4.0\%), Malathion (5.0\%), Alpha-cypermethrin $(0.5 \%)$ and Cyfluthrin $(0.15 \%)$. Batches of 20-25 females of individual species, i.e. Anopheles annularis, An. culicifacies and An. stephensi, were exposed to the diagnostic doses of each insecticide, using insecticide impregnated papers supplied by WHO, besides control of each insecticide group viz. organochlorines, organophosphates and synthetic pyrethroids. After one hour exposure, the experimental females were transferred to holding tubes and the mortality was recorded after 24 hours. Wherever, the mortality in control was observed between 5-15 percent, the observed mortality was corrected using Abbot's Formula ${ }^{[5]}$. The insecticide resistance status was determined using WHO criteria: mortality below 80.0 per cent Resistant, between $80-98$ per cent Intermediate Resistant, above 98 per cent Susceptible.

All the experiments were conducted in the field conditions. The temperature ranged from 26-30 degree Celsius and relative humidity $70-80$ per cent.

\section{Results and Discussion}

The results of the experiments insecticide resistance status of malaria vector species against insecticides, being used under National Malaria Control Programme, have been given in Table 1. An. culicifacies in Bhagora, a canal irrigated village was found resistant to DDT (Mortality: 48.0\%), intermediate resistant to Malathion (Mortality: $80.0 \%$ ) and susceptible to Alpha Cypermethrin (Mortality: 100.0\%) and Cyfluthrin (Mortality: 100.0\%). An. annularis in this village exhibited resistance to both DDT (Mortality: 56.0\%) and Malathion (Mortality: 72.0\%), however, susceptible to both the synthetic pyrethroids viz., Alpha Cypermethrin (Mortality: 100.0\%) and Cyfluthrin (Mortality: 100.0\%).

In Kheda, another canal irrigated village, An. culicifacies was found susceptible to DDT (Mortality: 100.0\%), whereas An. annularis was tested resistant to DDT (Mortality: $70.0 \%$ ) and susceptible to Alpha Cypermethrin (Mortality: 100.0\%) and Cyfluthrin (Mortality: 100.0\%). An. stephensi in this village was found susceptible to Alpha Cypermethrin (Mortality: $100.0 \%$ ).

In Potaliya, a rain-fed irrigation village, An. culicifacies was found resistant to DDT (Mortality: 55.0\%) as well as to Malathion (Mortality: 60.0\%), however, was susceptible to Alpha Cypermethrin (Mortality: 100.0\%) and Cyfluthrin (Mortality: 100.0\%). An. annularis in this village exhibited resistance to DDT (Mortality: 40.0\%), intermediate resistance to Malathion (Mortality: $85.0 \%$ ) but susceptible to Alpha
Cypermethrin (Mortality: 100.0\%) and Cyfluthrin (Mortality: $100.0 \%)$.

In Kotda, another rain-fed irrigation village, An. culicifacies was found intermediate resistant to DDT (Mortality: 92.0\%) and susceptible to Malathion (Mortality: 100.0\%) and Alpha Cypermethrin (Mortality: 100.0\%), however, against Cyfluthrin the species exhibited intermediate resistance (Mortality: 96.0\%).

An. culicifacies in Khajura, a rain-fed irrigation village, exhibited resistance to DDT (Mortality: 80.0\%) and Malathion (Mortality: 64.0\%), however, was found susceptible to Alpha Cypermethrin (Mortality: 100.0\%) and Cyfluthrin (Mortality: 100.0\%).

An. culicifaies, except one canal irrigated village Kheda, where it was found susceptible to DDT (Mortality: 100.0\%), was found either resistant (Mortality: $<80.0 \%$ ) or intermediate resistant (Mortality: 80.0-98.0\%). Against Malathion An. culicifacies was found susceptible in one village Kotda, a rain-fed irrigation village (Mortality: $80.0 \%$ ), whereas in all other villages, it was found either resistant (Mortality: $<80.0 \%$ ) or intermediate resistant (Mortality: 80.0-98.0\%). Against synthetic pyrethroids An. culicifacies was found susceptible to both Alpha Cypermethrin and Cyfluthrin (Mortality: 100.0\%), except one rain-fed irrigation village Kotda, where against Cyfluthrin, the species exhibited intermediate resistance (Mortality: 96.0\%). This is a first report of synthetic pyrethroid resistance from Rajasthan and is a matter of concern as synthetic pyrethroids have been inducted in the national control programme as emergency insecticides for the control of those malaria vector species who exhibit multiple resistance against organochlorine, organophosphate and carbamate class of insecticides.

An. annularis, a secondary vector species of malaria, was found resistant to DDT in both canal irrigated and rain-fed irrigation villages (Mortality: $<80.0 \%$ ), however, against Malathion it exhibited resistance in canal irrigated village Bhagora (<Mortality: $80.0 \%$ ) and intermediate resistance in rain-fed irrigation village Potalia (Mortality: 80.0\%). However, against Alpha Cypermethrin and Cyfluthrin the species was found totally susceptible in both canal irrigated and rain-fed irrigation villages (Mortality: 100.0\%).

$A n$, stephensi, a common urban mosquito vectors, was tested only against Alpha Cypermethrin synthetic pyrethroid in a canal irrigated village Kheda and the species was found totally susceptible (Mortality: $100.0 \%$ ).

In the study area An. culicifacies have exhibited triple resistance, showing resistance to DDT, Malathion and intermediate resistance to Cyfluthrin, however, An. annularis exhibited double resistance to DDT and Malathion. An. stephensi was tested only against Alpha-Cypermethrin and was found totally susceptible.

An. culicifacies in other parts of Rajasthan have also exhibited resistance to DDT and intermediate resistance to Propoxur in Bikaner district, however, An. annularis exhibited resistance to both DDT and Proposure ${ }^{[6]}$. Both An. culicifacies and An. annularis were found susceptible to Permethrin. Singh \& Bansal studied current response of An. stephensi to six insecticides in 3 desert districts i.e. Barmer, Jodhpur \& Pali and found that the species was resistant to DDT and Dieldrin, partial resistant to Malathion and susceptible to Fenitrothion, Propoxur and Permethrin ${ }^{[7]}$. Tiker et al. (2011) have reported intermediate resistance in An. stephensi against Deltamethrin from Jodhpur district and resistance against Malathion ${ }^{[8]}$. 
Sharma et al. (2007) reported triple resistance in An. culicifacies against DDT, Malathion and Deltamethrin in some tribal districts of Chhatisgarh state, where synthetic pyrethroids have been used as indoor residual spray (IRS) ${ }^{[10]}$. Bhatt et al. (2012) also reported resistance in An. culicifacies against DDT and Malathion, however, intermediate resistance against Deltamethrin in Chhattisgarh state ${ }^{[11]}$. In 2012 only Singh et al. from Maharastra reported that both An. culicifacies and An. annularis were found resistant to DDT and intermediate resistant to Malathion and Deltamethrin as well ${ }^{12}$. Dhiman et al. (2014) reported that An. annularis in north-eastern parts of India was resistant to DDT and intermediate resistant to Deltamethrin ${ }^{[13]}$.

Raghavendra et al. (2014) studied susceptibility status of $A n$. culicifacies in 32 districts of the country and found that the species was resistant to DDT and Malathion, however, against Deltamethrin the species exhibited susceptibility in 17 districts, intermediate resistance in 11 districts and resistance in 04 districts ${ }^{[14]}$. Sahu et al. (2015) reported triple resistance in An. culicifacies from five districts of Orissa state against DDT, Malathion and Deltamethrin, which were being used in malaria control programme in the area ${ }^{[15]}$. In 2019, Sahu et al. (2019) also reported multiple resistance in An. culicifacies from east central India against DDT, Malathion and Deltamethrin ${ }^{[16]}$.

Vector control is mainly based on the chemical means and in the present context is relied on the use of synthetic pyrethroids either as indoor residual spray or in impregnation of bed-nets. The development of resistance against these compounds, as indicated with the findings of the present study and published reports from different parts of the country, alarms the use of these compounds very judiciously and efficiently and considering the impact of agricultural pesticides in the form of cross-resistance. Periodic monitoring and determination of current susceptibility status of these compounds in important malaria vector species of a particular area need to be prioritized.

Table 1: Susceptibility status of malaria vector species collected from study villages of Banswara district against different insecticides

\begin{tabular}{|c|c|c|c|c|c|}
\hline $\begin{array}{l}\text { Study } \\
\text { Areas }\end{array}$ & Village & Species & Insecticide \& diagnostic Dose & $\begin{array}{c}\text { Percent Corrected Mortality } \\
(\%)\end{array}$ & $\begin{array}{c}\text { Suscep-tibility } \\
\text { Status* }\end{array}$ \\
\hline \multirow{12}{*}{$\begin{array}{l}\text { Partapur BPHC- } \\
\text { (Canal Irrigated) }\end{array}$} & \multirow{8}{*}{ Bhagora } & \multirow{4}{*}{ An. culicifacies } & DDT $4.0 \%$ & 48.0 & $\mathrm{R}$ \\
\hline & & & Malathion 5.0\% & 80.0 & IR \\
\hline & & & Alpha cypermethrin, $0.05 \%$ & 100.0 & $\mathrm{~S}$ \\
\hline & & & Cyfluthrin, $0.15 \%$ & 100.0 & $\mathrm{~S}$ \\
\hline & & \multirow{4}{*}{ An. annularis } & DDT, $4.0 \%$ & 56.0 & $\mathrm{R}$ \\
\hline & & & Malathion, $5.0 \%$ & 72.0 & $\mathrm{R}$ \\
\hline & & & Alpha cypermethrin, $0.05 \%$ & 100.0 & $\mathrm{~S}$ \\
\hline & & & Cyfluthrin, $0.15 \%$ & 100.0 & $\mathrm{~S}$ \\
\hline & \multirow{4}{*}{ Kheda } & An.stephensi & Alpha cypermethrin, $0.05 \%$ & 100.0 & $\mathrm{~S}$ \\
\hline & & An. culicifacies & DDT, $4.0 \%$ & 100.0 & $\mathrm{~S}$ \\
\hline & & \multirow{2}{*}{ An. annularis } & DDT, $4.0 \%$ & 70.0 & $\mathrm{R}$ \\
\hline & & & Alpha cypermethrin, $0.05 \%$ & 100.0 & $\mathrm{~S}$ \\
\hline \multirow{16}{*}{$\begin{array}{l}\text { Kushal-garh BPHC- } \\
\text { (Rain Water Irrigated) }\end{array}$} & \multirow{8}{*}{ Potalia } & \multirow{4}{*}{ An. culicifacies } & DDT, $4.0 \%$ & 55.0 & $\mathrm{R}$ \\
\hline & & & Malathion, $5.0 \%$ & 60.0 & $\mathrm{R}$ \\
\hline & & & Alpha cypermethrin, $0.05 \%$ & 100.0 & $\mathrm{~S}$ \\
\hline & & & Cyfluthrin, $0.15 \%$ & 100.0 & $\mathrm{~S}$ \\
\hline & & \multirow{4}{*}{ An. annularis } & DDT, $4.0 \%$ & 40.0 & $\mathrm{R}$ \\
\hline & & & Malathion, $5.0 \%$ & 85.0 & IR \\
\hline & & & Alpha cypermethrin, $0.05 \%$ & 100.0 & $\mathrm{~S}$ \\
\hline & & & Cyfluthrin, $0.15 \%$ & 100.0 & $\mathrm{~S}$ \\
\hline & \multirow{4}{*}{ Kotada } & \multirow{4}{*}{ An. culicifacies } & DDT, $4.0 \%$ & 92.0 & IR \\
\hline & & & Malathion, $5.0 \%$ & 100.0 & $\mathrm{~S}$ \\
\hline & & & Alpha cypermethrin, $0.05 \%$ & 100.0 & $\mathrm{~S}$ \\
\hline & & & Cyfluthrin, $0.15 \%$ & 96.0 & IR \\
\hline & \multirow{4}{*}{ Khajura } & \multirow{4}{*}{ An. culicifacies } & DDT, $4.0 \%$ & 80.0 & IR \\
\hline & & & Malathion, $5.0 \%$ & 64.0 & $\mathrm{R}$ \\
\hline & & & Alpha cypermethrin, 0.05 & 100.0 & $\mathrm{~S}$ \\
\hline & & & Cyfluthrin, $0.15 \%$ & 100.0 & $\mathrm{~S}$ \\
\hline
\end{tabular}

$*$ S- Susceptible (Mortality >98\%), R- Resistant (Mortality > 80\%), IR- Intermediate

Resistant (Mortality 80-98\%).

\section{Acknowledgements}

The authors express deep sense of gratitude to the Director, ICMR-NIIRNDC, Jodhpur for providing facilities to conduct the study. Department of Science \& Technology, Govt. of India is gratefully acknowledged for financial support.

\section{References}

1. Raghavendra Kamaraju, Sharma Poonam, Velamuri Verma, Vaishali Elamathi, Natarajan Barik, Kumar Tapan et al. Temporo-spatial distribution of insecticideresistance in Indian malaria vectors in the last quarter- century: Need for regular resistance monitoring and management. Journal of Vector Borne Diseases 2017;54:111-130.

2. Yadav RS, Raghavendra K, Velamuri PS, Verma V, Uragayala $S$. Insecticide resistance in vectors of malaria in India and its management. In Vector Biology and Control - An Update for Malaria Elimination Initiative in India, ed. Vas Dev. Allahabad, India: National Academy of Sciences 2020, 129-148.

3. WHO global malaria programme: Global plan for insecticide resistance management in malaria vectors. 
Geneva, Switzerland: World Health Organization 2012, 130.

4. World Health Organization (WHO). Test procedures for insecticide resistance monitoring in malaria vector mosquitoes. Geneva: WHO 2013.

5. World Health Organization. Resistance of vectors ad reservoirs of disease to pesticides. $10^{\text {th }}$ report of the expert committee on vector biology and control. WHO Technical Report Series 1986;737:86.

6. Abbott WS. A method of computing the effectiveness of an insecticide. Journal of Economic Entomology 1925;18:265-267.

7. Bansal SK, Singh, Karam V. Insecticide susceptibility status of some anophelines I district Bikaner, Rajasthaj. Indian Journal of Malariology 1996;33:1-6.

8. Singh Karam V, Bansal SK. Current status of Anopheles stephensi response to various insecticides in some areas of the Thar Desert. Indian Journal of Medical Research 1996;103:299-303.

9. Tikar SN, Mendki MJ, Sharma AK, Sukumaran D, Veer $\mathrm{V}$, Prakash S et al. Resistance status of the malaria vector mosquitoes, Anopheles stephensi and Anopheles subpictus towards adulticides and larvicides in arid and semi-arid areas of India. Journal of Insect Science 2011;11: 85.

10. Sharma SN, Shukla RP, Mittal PK, Adak T, Subbarao SK. Insecticide resistance in malaria vector Anopheles culicifacies in some tribal districts of Chhattisgarh, India. Current Science 2007;92:1280-82.

11. Bhatt RM, Sharma SN, Barik TK, Raghavendra K. Status of insecticide resistance in malaria vector, Anopheles culicifacies in Chhattisgarh state, India. Journal of Vector Borne Diseases 2012;49:36-38.

12. Singh RK, Mittal PK, Gourshettiwar MP, Pande SJ, Dhiman RC. Susceptibility of malaria vectors to insecticides in Gadchiroli district (Maharashtra), India. Journal of Vector Borne Diseases 2012;49:42-44.

13. Dhiman S, Rabha B, Goswami D, Das NG, Baruah I, Bhola RK et al. Insecticide resistance and human blood meal preference of Anopheles annularis in AssamMeghalaya border area, Northeast India. J Vector Borne Dis 2014;51:133-136.

14. Raghavendra K, Barik TK, Sharma SK, Das MK, Dua VK, Pandey A et al. A note on the insecticide susceptibility status of principal malaria vector Anopheles culicifacies in four States of India. Journal of Vector Borne Diseases 2014;51:230-234.

15. Sahu SS, Gunasekaran K, Vijayakumar T, Jambulingam P. Triple insecticide resistance in Anopheles culicifacies: a practical impediment for malaria control in Odisha State, India. Indian Journal of Medical Research 2015; 142:S59-S63.

16. Sahu Sudhansu Sekhar, Sonia Thankachy, Smrutidhara Dash, Subramanian Swaminathan, Gunasekaran Kasinathan, Jambulingam Purushothaman. Multiple insecticide resistance in Anopheles culicifacies s.l. (Diptera: Culicidae) in east-central India. Pathogens and Global Health 2019;113:352-358. 